\title{
Studies of ignition and combustion of coals subjected to electrochemical activation
}

\author{
Artem Kuznetsov ${ }^{1 *}$, Evgenii Butakov ${ }^{1}$, Anatoly Burdukov ${ }^{1}$, Egor $_{\text {Yaganov }}{ }^{2}$ \\ ${ }^{1}$ Institute of Thermophysics SB RAS, Novosibirsk, Russia \\ ${ }^{2}$ Open joint-stock company Sibtechenergo, Novosibirsk, Russia
}

\begin{abstract}
Coal is one of the most important energy sources in the world. According to forecasts, by 2020 , the share of coal in the global energy sector will reach $50 \%$, primarily due to the very likely reduction in oil and gas consumption, as well as the revision of the policy on the development of nuclear energy. For thermal power plants with pulverized-coal boilers, a problematic economic and technological issue is ignition and lighting, carried out with high-reaction fuel - gas, fuel oil, and diesel fuel. The cost of this fuel is much higher than the cost of coal itself, which means that the introduction of new technologies that allow excluding petroleum products from the energy processes that take place at the CHP plant is topical [1]. In this paper, the technology of electrochemical ignition, which is an alternative to gas and fuel oil ignition of power boilers, is studied.
\end{abstract}

The purpose of this work was to detect the influence of the consumption-dynamic parameters of the dust-air mixture on the efficiency of ignition of coal dust of Kuznetsk coal, and, to determine the optimal design and layout parameters of the ignition system.

The experiments were carried out on a large fire stand with a thermal power of $5 \mathrm{MW}$. The technological scheme of the fire stand is shown in Fig. 1. The main units and auxiliary systems of the fire stand are functionally related as follows [2]. Vibrant feeder of coal dust with a frequency converter with a capacity of up to $290 \mathrm{~kg} / \mathrm{h}$ provides fuel to the air ejector with air capacity of $100 \mathrm{~m}^{3} / \mathrm{h}$. As a working medium, compressed air with a pressure of 6 bar is used. This ejector is designed for stable supply of coal dust to the electric arc block. Further, the primary dust-air mixture enters the second ejector with a capacity of up to 600 $\mathrm{m}^{3} / \mathrm{h}$, in which it mixes with air from a blower with a frequency converter. The second ejector is needed to regulate the flow of primary air to the arc block [3,4]. After this ejector, the dust-air mixture enters the electric arc block of the system, in which its primary ignition occurs. The ignited particles of coal dust enter the first stage of the reactor, where its active burning takes place. Solid admixtures of combustion products (ash and unburned coal dust) are separated in a cyclone, after which the gases are released by the smoke exhaust into the atmosphere.

* Corresponding author: temkansu@yandex.ru 


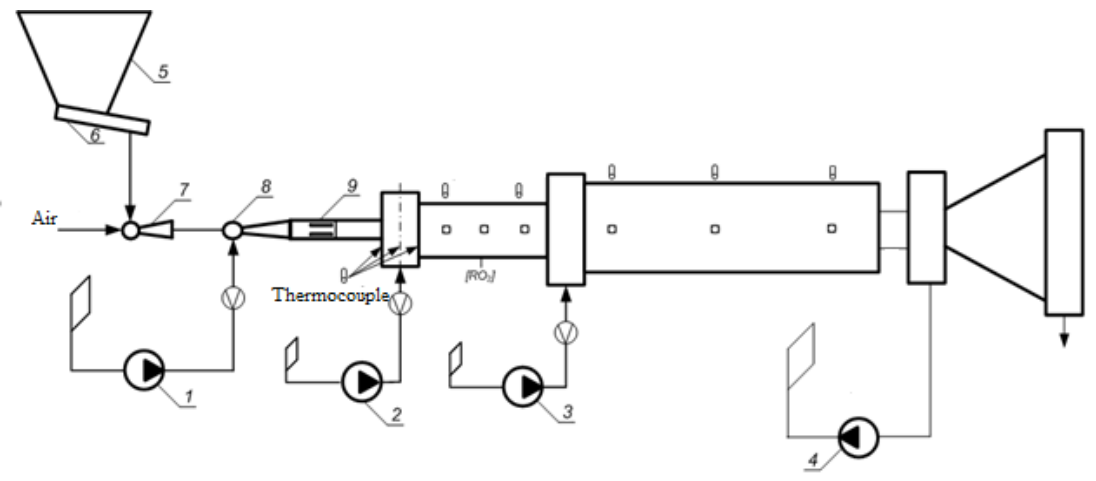

Fig.1. Technological scheme of the stand: 1,2,3 - blowers, 4 - smoke exhauster, 5 - coal dust batcher, 6 - vibrator feeder, 7,8 - ejectors, 9 - electric arc block (EAB).

The procedure for carrying out the experiments is determined by the sequence of preparation and measurement of the parameters. In the cold purge mode, the air flow to the first and second ejectors was measured. The inputs necessary for the experiment, as measured by the Prandtl tube and the differential manometer TESTO-435, were calculated and adjusted. Debugging of the gas and temperature analysis systems before the beginning of the experiment, testing the temperature sensors and the gas analysis system for the breakage of the measuring circuits, checking the contamination of the thermocouples and the purging of the gas pipelines from the measurement point to the gas analyzer were performed. Dust from the feeder was fed into the furnace using an ejector and a compressed air system. The initiation of the ignition of a pulverized-coal flame was carried out using an electric arc block (Fig.2).
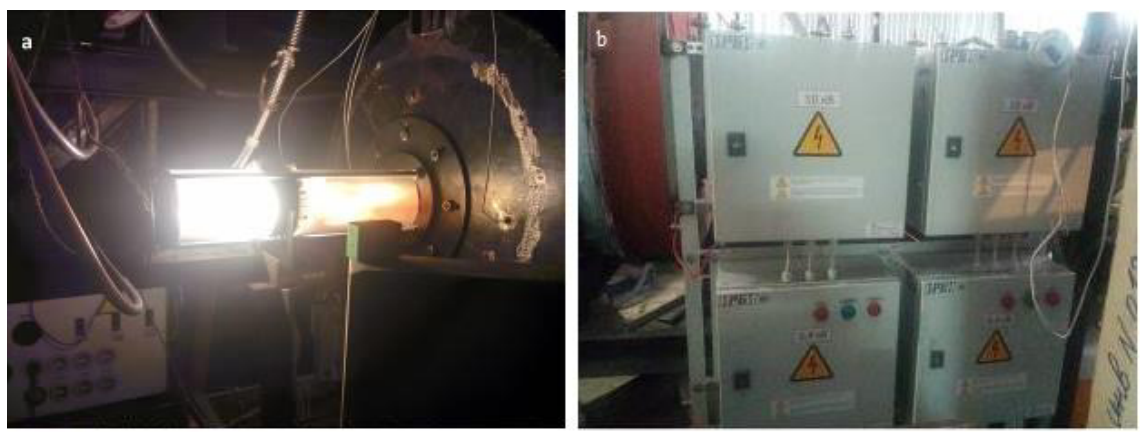

Fig.2. Electrochemical fuel system a) working system of electrochemical ignition b) high and low voltage transformers

During the experiments, the temperature of the internal lining of the muffle, the combustion chamber and the afterburner was measured. Combustion products were analyzed with the help of the gas analyzer. After the afterburning chamber, the fly ash was taken-abductions according to the isokinetic sampling method, as well as analysis of the flue gas composition with the help of an additional TESTO-340 gas analyzer. The main selection of ash was made from the cyclone bunker in front of the smoke exhauster.

The efficiency of ignition of the dust-air mixture flow was studied as a function of the mass flow of dust. Condition - constant volumetric flow of primary air. In experiments with a constant flow of primary air at a level of $200 \mathrm{~m} 3 / \mathrm{h}$, the flow rate of coal dust supplied 
for combustion was changed from $42 \mathrm{~kg} / \mathrm{h}$ to $290 \mathrm{~kg} / \mathrm{h}$. The concentration of dust in the flow thus varied from 0.17 to 1.13 , and excess air varied from 0.89 to 0.13 . A significant difference between the excesses measured in the experiments in the chamber compared to the coefficients calculated based on the measured flows of fuel and air indicates an incomplete reaction (mixing) of oxygen with coal dust during its combustion. Only a part of the supplied air participates in the combustion of coal fuel after its ignition in EAB. Analyzing the obtained data, it should be noted that nitrogen oxides decrease with electrochemical combustion, with an increase in excessively organized air supply. This is because when feeding more fuel into the $\mathrm{EAB}$, the process of ignition intensifies - the torch in the combustion chamber is formed instantaneously. A greater number of carbon particles falls into the area of the electrodes and passes through electric arcs and their electric fields. The amount of fuel supplied determines the amount of heat released during combustion. The increase in heat in the experiments leads to an increase in the rate of heating of the lining and the combustion chamber itself-conditions are created for the thermal heating of coal particles, the escape of volatile and combustion of carbon. The content of combustibles in the entrails practically does not change in the experiments, with electrochemical combustion and with rectilinear fuel supply only $40-50 \%$ of the carbon contained in coal dust burns into the combustion chamber. The reason for this is the lack of conditions for the oxidant to mix with the carbon. In electrochemical combustion, combustion occurs due to the interaction of carbon particles with transport air at the same velocities of both. Initiation of the same combustion occurs in the EAB [5] of the system without thermal preparation of fuel.

The optimal position of electrodes for effective ignition of coal dust was determined. In the experiments, the position of the electrodes in the EAB was changed. The layout of the electrodes in the EAB is shown in Fig. 3. With a constant flow of primary air at $215 \mathrm{~m}^{3} / \mathrm{h}$, the flow rate of coal dust supplied for combustion was changed from $50 \mathrm{~kg} / \mathrm{h}$ to $220 \mathrm{~kg} / \mathrm{h}$. The concentration of dust in the stream varied from 0.19 to 0.87 , while excess air varied from 0.81 to 0.18 . When coal dust was injected into the EAB, the ignition was instantaneous. However, if compared with the previous location of the electrodes in the experiments, the glow of electric arcs with coal dust became worse. Visually, the dust was clearly trailing along the bottom of the quartz tube. The quartz camera itself was quickly absorbed. Burning in the reactor and combustion chamber is stable from the moment of coal dust supply, and the set of temperatures is stable.

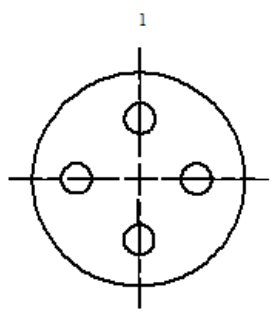

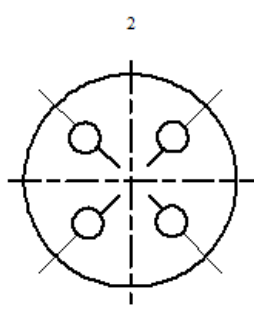

$\mathrm{Cr}, \%$

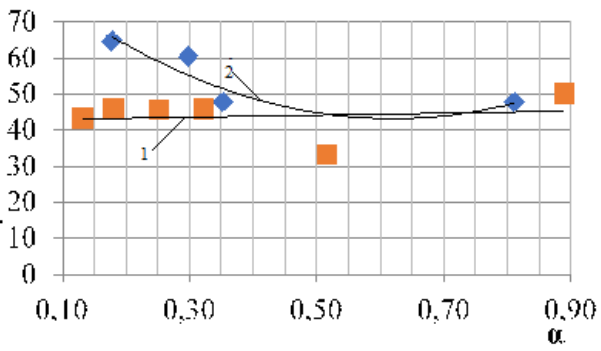

Fig.3. a) scheme of the location of electrodes, 1 - "Rhombus", 2 - Square" (45-degree rotation) b) dependences of the change in the content of combustibles in the entrainment on the coefficient of excess air in the layout of the electrodes "Square" and "Rhombus"

Comparing the results obtained with respect to the content of combustibles in entrails with previous experiments, it should be noted that with reduced excess air, in conditions of supplying more fuel, the changed scheme of the location of the "Square" electrodes 
worsens fuel more than in the previously tested "Rhombus" scheme. So, under the "Rhombus" scheme, the content of combustibles in the entrainment did not exceed $45 \%$ in the whole range of the investigated excess air, and in the "Square" scheme the range of this value increased to $65 \%$.

\section{Conclusion}

1 The maximum possible speed of the dust-air mixture in the cross section of the electrode installation (electric arc block) is $20 \mathrm{~m} / \mathrm{s}$. Further increase in speed is impossible due to the breakthrough of coal particles of electric arcs.

2 The minimum possible speed of the dust-air mixture in the cross section of the electrodes is $6 \mathrm{~m} / \mathrm{s}$. A further reduction in speed leads to separation of coal dust in the electric arc block and its heating.

3 The minimum fuel consumption for combustion is not less than $50 \mathrm{~kg} / \mathrm{h}$ for Kuznetskiy coal with a maximum excess of supply air of not more than 0.8 .

4 When coal dust is supplied to the operating electric arc unit, the ignition of the fuel takes place instantaneously, regardless of the amount of primary air flow.

5 Preheating the flue gases to the maximum temperature at a distance of half a meter occurs at a speed of $30-40^{\circ} \mathrm{C} / \mathrm{min}$. Stabilization of the combustion regime - the output to a constant oxygen content occurs within 2-5 minutes, depending on the excess air.

6 Burnout of coal dust is also incomplete. Visually the ash has a dark color, which indicates a significant underburning of the fuel. The relative decrease in the yield of volatiles in the selected samples was $50-75 \%$, and the reduction of carbon was $30-50 \%$.

7 When the electrodes are positioned according to the "Square" scheme, the burnout of the fuel is worse than under the "Rhombus" scheme. So, under the "Rhombus" scheme, the content of combustibles in the entrainment did not exceed $45 \%$ in the whole range of the investigated excess air, and in the "Square" scheme the range of this value increased to $65 \%$.

The work was financially supported by the Russian Ministry of Education and Science, according to Subsidiary Agreement No. 14.607.21.00150 (unique project identifier RFMEFI60716X0150).

\section{References}

1. V.N. Churashev, G.V. Chernova, Problems of substitution of fuel oil in heat power engineering, New technologies of fuel compression: their current state and future use: Proc. All-Russia. Scientific-techn. Seminar. Moscow 262 (2001)

2. A.P. Burdukov, E.B. Butakov, V.I. Popov, M.Yu. Chernetskiy, N.S. Chernetskaya, Thermal Science. 20, 23 (2016)

3. A.S. Koshkarov, Y.I. Naumov, S.F. Nikolayev, A.A. Shinkarev, RF Patent No. 2498159 (2013) (in Russian)

4. Y.I. Naumov, S.F. Nikolayev, A.A. Shinkarev, Proc. IX All-Russian conferences with international participation «Combustion of solid fuel »Novosibirsk, November 22-25, 2015.

5. M.F. Zhukov, E.I. Karpenko, V.S. Peregudov, Low-temperature plasma 15, 304 (1995) [in Russian] 